\title{
الوضع الإنسانيّ المعاصر بين الانفتاح والسيّولة
}

أ.م. د. علي عبّود المحمّداويّ

كلية الآداب/ جـامعة بغداد

"أصبح للقلسفة نفوذ سياسيّ عميق على وعي الجمهور،.. إلّا أنَّ التفكير الفلسفيّ قد سلتك في الوقت نفسـه اتجاهـاً جدياً وهو الاتجاه الذي حوله إلى نقد واقعيّ وعيانيّ للعلم...؛ ولذلك لايمكنتا أبداً أنْ نعتبر أنَّ التأويل العلمـاويّ للعلم والنقد

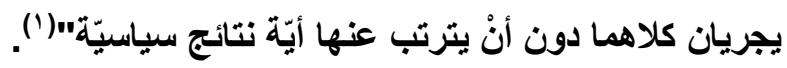

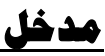

تُعدُّ مسألة البحث في الوضـع البشريّّ- العموميّ، و المشترك، و الذي يحاط بعالم السياسـة، من الموضو عات القديمـة المتجددة، والتي لاتنفك انسكاباً في و اقع يجدد نفسه، وفكر ينبجس بنظريات جديدة، وفي كل لحظة من تلك اللحظات نجد أنفسنا

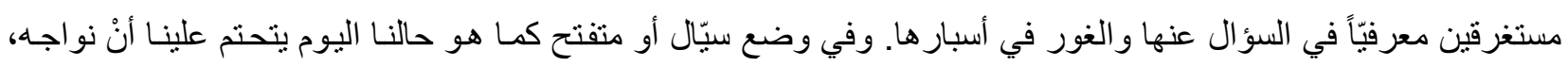

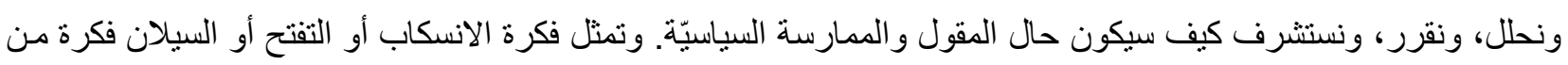

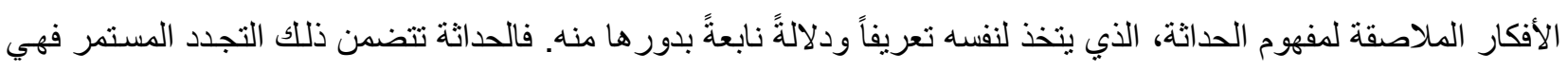
ذلك السيّال دوماً.

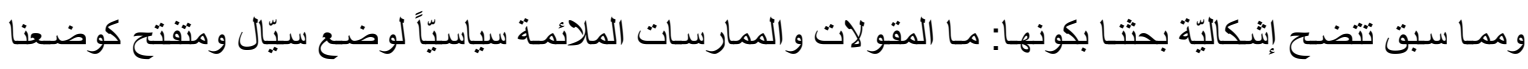

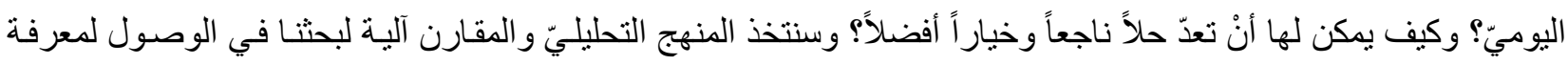

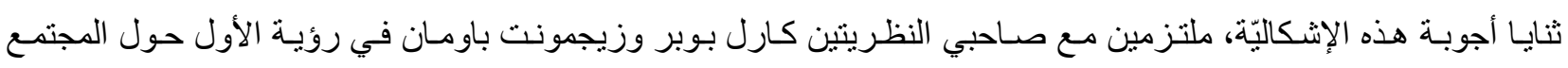
المفتوح، ورؤية الثاني في الوضع البشريّ السيّال.

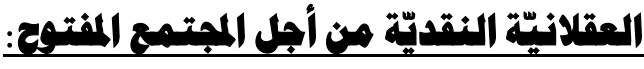

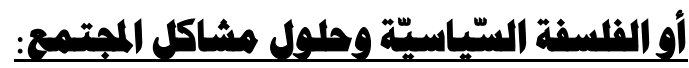

إذا كانتُ الحياة عبارة عن سلسلة من حل المشكلات، فالفلسفة السيّاسيّة هي من أهم حلقات هذه السّلسلة عند كارل

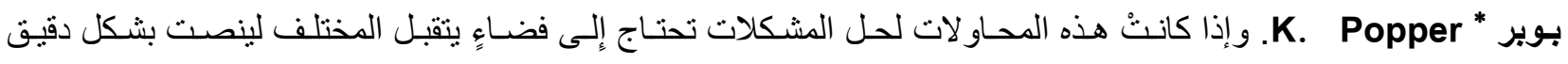
للخيار ات المختلفة فعليه ان يكون في مجتمع خـالٍ من الانغلاق و الدو غمائيّة: إنَّهـ المجتمع المفتوح؛ لذللك رأى بوبر ضرورة

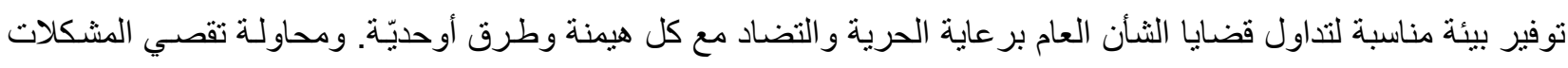

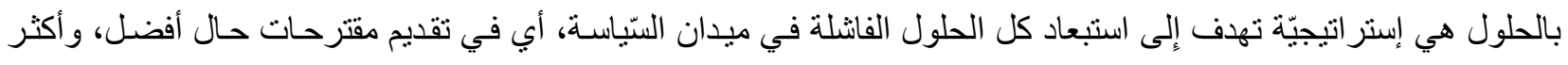

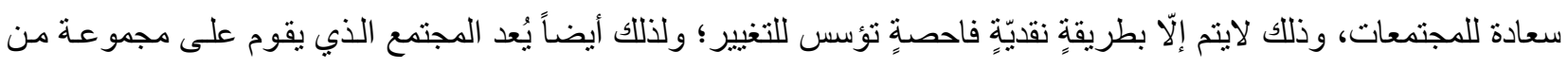

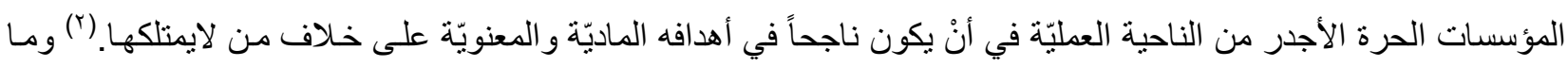

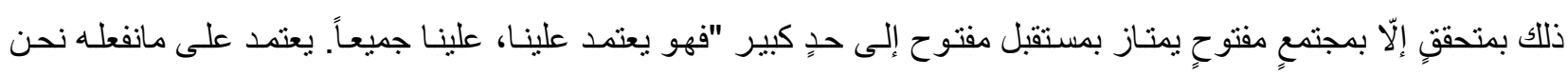

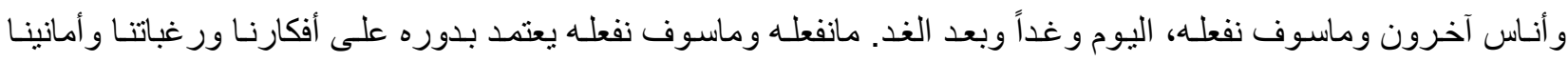

ومخاوفنا، كما يعتمد على كيف نرى العالم وكيف نحكم على إمكانيات المستقبل المفتوحة إلى حدٍ كبير" (").

ولما سبق نجد أنَّ بوبر قد قرأ المجتمع المتفتح بوصفه مجتمعاً منظماً لحل المشكلات والتصدي لها دوماً، والارتقاء بعد كل تجربة لما هو قادم و أفضل و المجتمع المفتوح عند بوبر سيشابه فكرنه عن المجتمع العلميّ، "الذي يسمح بتطبيق منهجـه

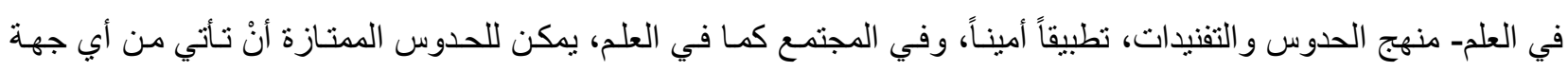


بالإبداع الحر، ليس بالضرورة من أعلى. ويتوجب بالتـالي أنْ يكون تدفق المعلومـات صـاعداً أيضـاً من القاعدة إلى القــة....

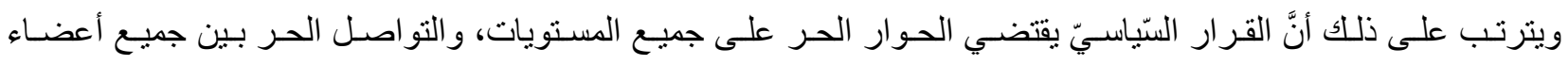
المجتمع.... فإنَّ الخطة السيّاسيّة في المجتمع المفتوح يتعين أنْ تُعرض للاختبـار النقديّ للنتائج المترنبـة على تتفيذها، وللنقد الموجه إليها من القاعدة، شاملة المعارضين و المناهضين للخطة" (؛).

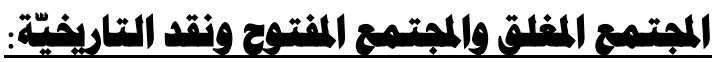

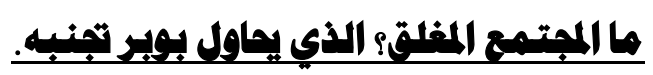

إنّه المجتمع الذي يسميه بوبر بالسحريّ و القبليّ، و الذي يحدد معالم لبدايته ونهايته، دونما أنْ يكون قد علق أملاً على التى متغير ات الرغبة و التفكر و النقد و الإمكانات التي قد تتنج من سلوكيات الإنسان تجاه بني جنسه و الطبيعة. "فالمجتمع المغلق يشبه بـانه القطيع أو القبيلة في أنَّه وحدة شبه عضويّة يرتبط أعضاؤ ها بعضهم ببعض برو ابط شبه بايولوجيّة، كالنسب و الحياة المشتركة،

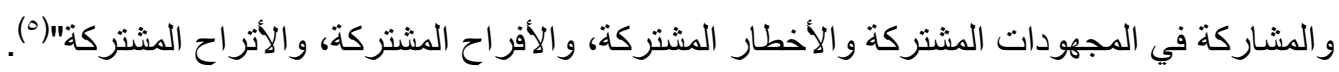
ينتج عن المجتمعات المغلقة كل إمكانيات الاستبداد و العبودية لذلك يقول بوبر : "إنَّ تنبي موقف منـاهض للمساواة في الحياة السّياسيّة، أي في مجال المشكلات المتعلقة بسلطة إنسان على إنسان، لَهو على وجها التحديد ماينبغي أنْ اسميه جريمـة.

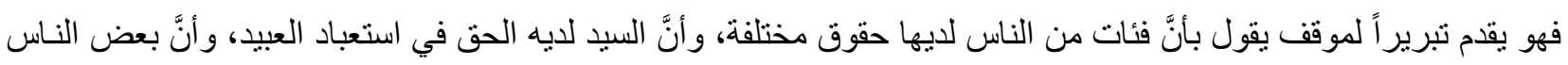

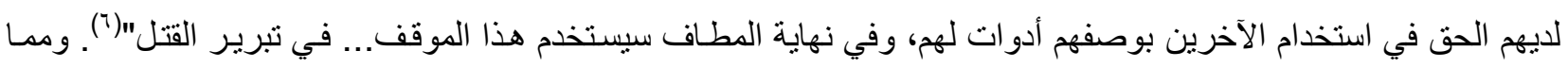
تقدم يبقى الأمل مفتوحاً في تبني مقو لات بالضد من كل هذه المقدمات التي رافق المجتمعات المغلقة و الأيديولوجيات التاريخيّة

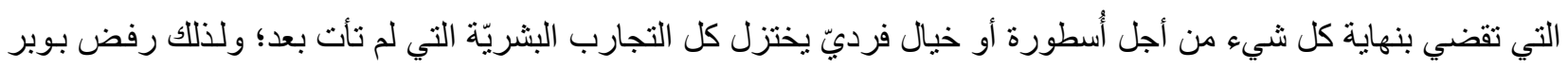

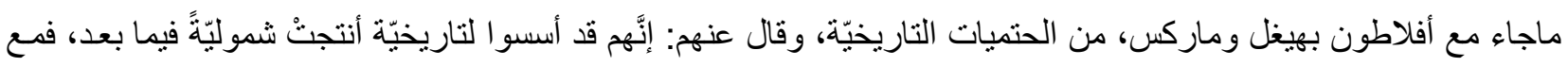

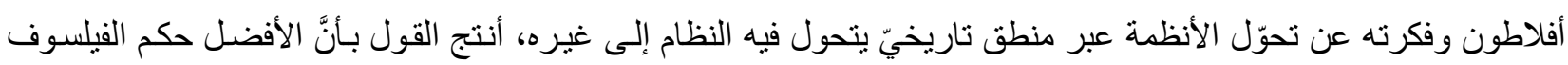

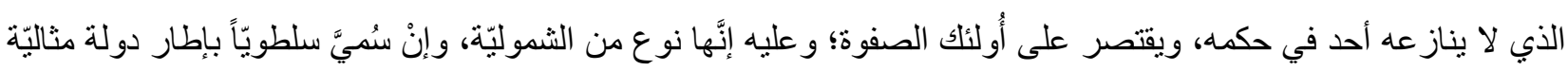

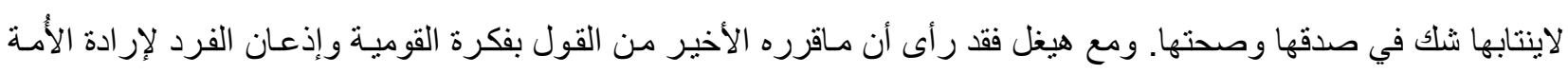

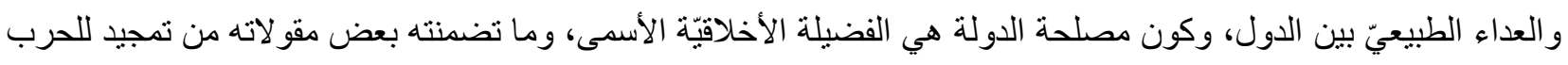

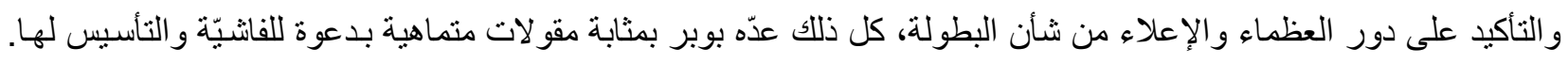

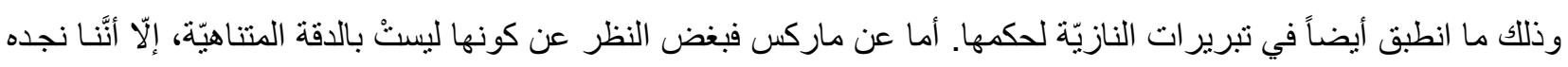

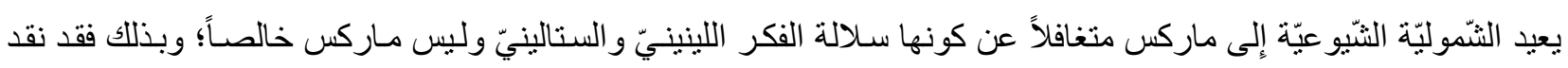

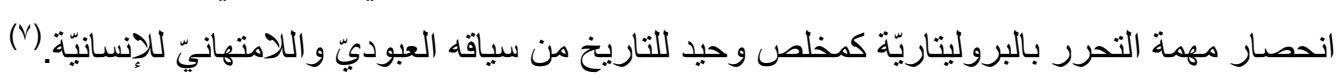
ومما سبق نجد بوبر يقرر بأنَّ التاريخ بلا معنى، لكن هذا الزعم حسب قوله: "لايعني أنَّ كل مايمكننا فعله تجاه

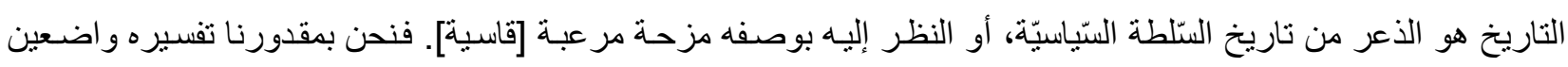

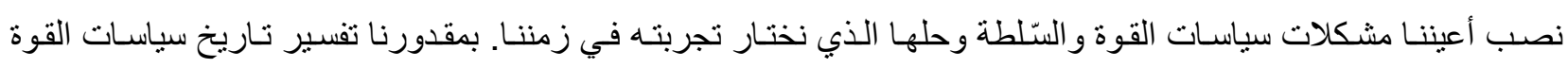

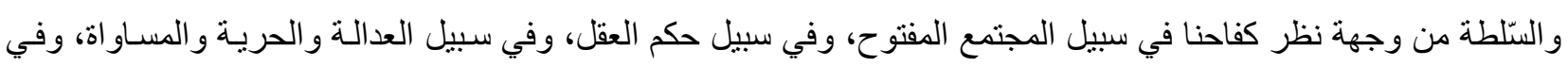

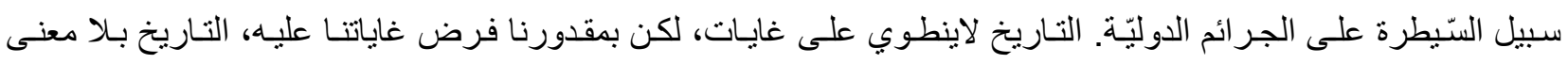

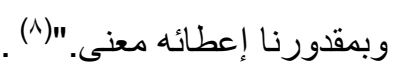

ويسرد بوبر خمس قضـايا يعدها بمثابـة مرنكز ات لنقد الحتميّة التاريخيّة التي تقود للانغلاق في تفسير المجتمعات

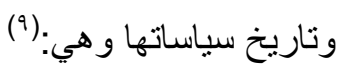


ا ـ تتأثر مسيرة التاريخ البشريّ نائثر اً قوياً بنمو المعرفة الإنسانيّة. r- لايمكن التنبؤ عقليّاً أو عمليّاً بطريقة النمو التي تحصل لأفكارنا ومعارفنا. r- مما سبق ينتج أنَّهَ لايمكن أنْ نتنبأ بمستقبل مسيرة التاريخ الإنسانيّ. ـ- - يجب أنْ نرفض كل إمكان نظريّ على قيام علم في ناريخ المجتمع كما في حال تاريخ الطبيعة. و لايمكن أنْ تكون هنالك نظرية عمية لتفسير التطور التاريخيّ على أساس التنبؤ. هـ إذن، فقد أخطأ المذهب التاريخيّ وكل نظريـة تقول بحتميـة التاريخ و إمكان التنبؤ بـه بانهيار الغايـات التي بعتمدها في

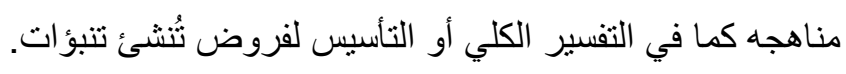
وما تجاوز هذه التاريخانيات وبؤسها إلّا بالمجتمع المفتوح؛ لذلك يتمم بوبر فيه القول: "إذا رغبنـا في أنْ نظلَّ بشراً،

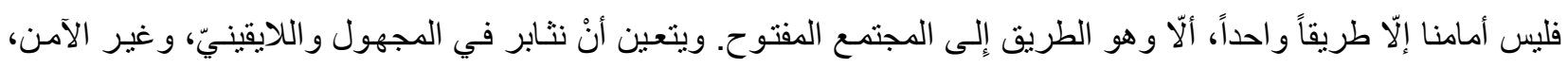

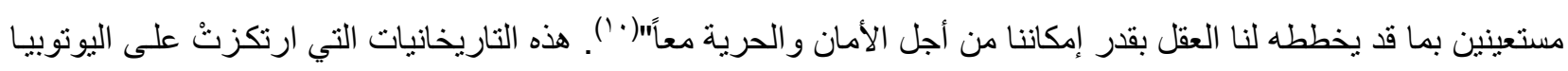

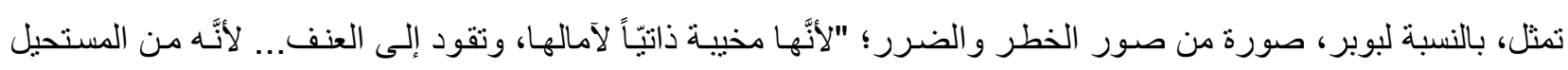

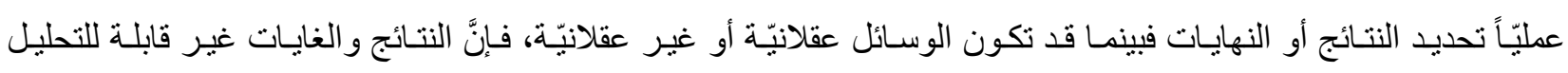

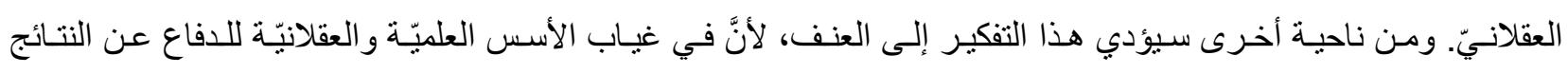

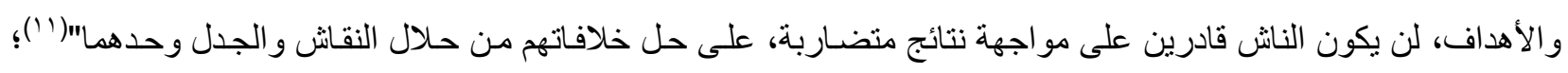

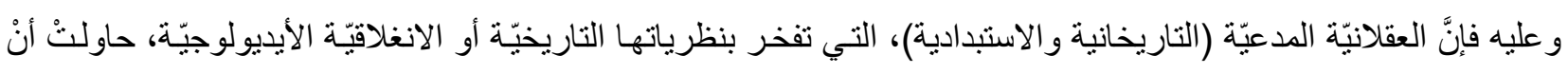

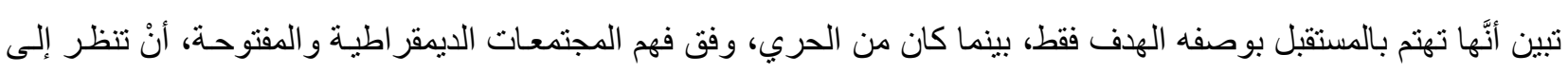

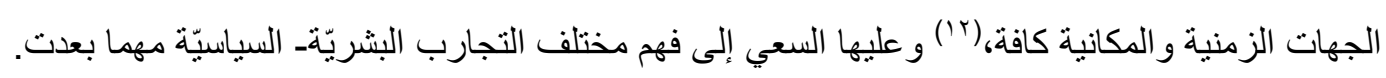

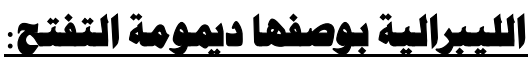

يدافع بوبر عن النموذج الليير اليّّ، ويتكلم عن وجود مبادئ للّيبر اليّة هي: السّيّادة و الديمقر اطيّة و التسـامح و الحريـة،

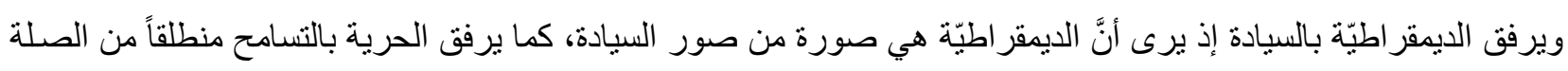

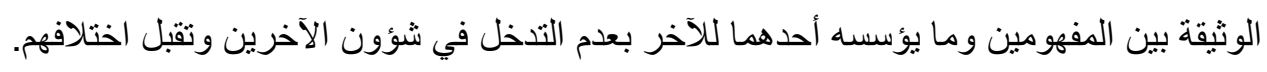
إذا كان سؤال من الذي يجب أنْ يحكم هو السؤ ال الثاغل للفلسفة التقليديّة السيّاسيّة منذ سقر اط و أفلاطون سؤ ال قد

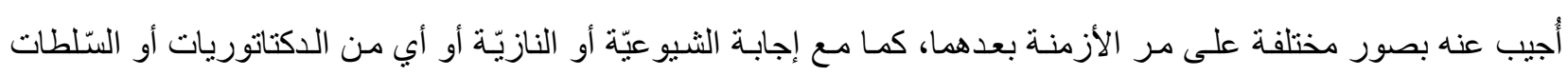

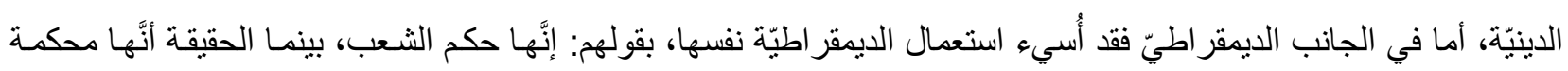

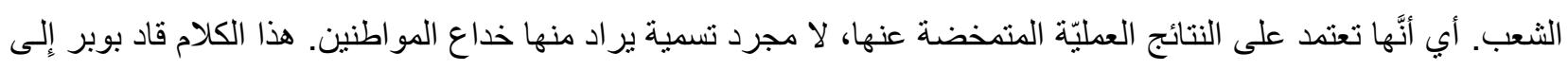

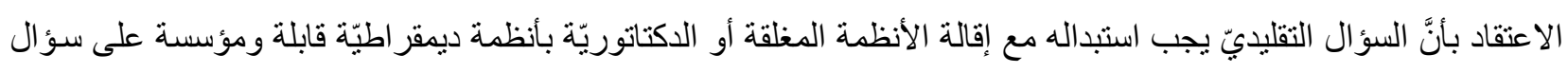

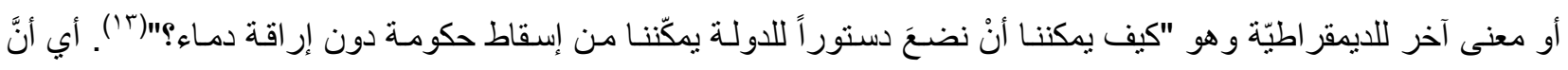

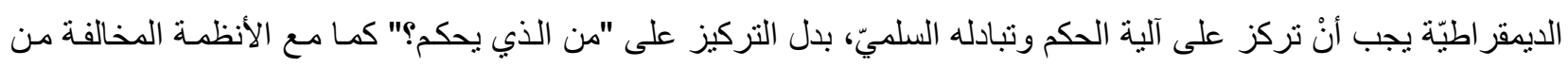

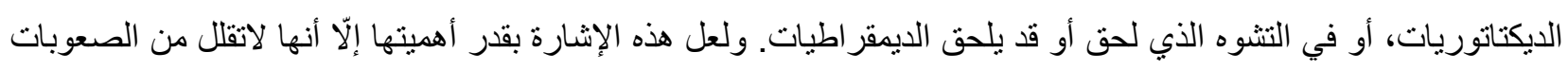

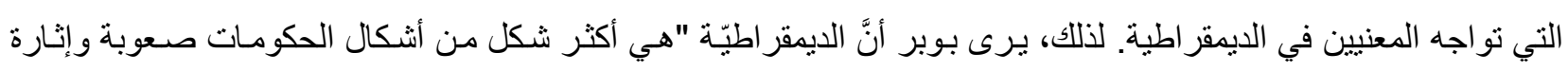

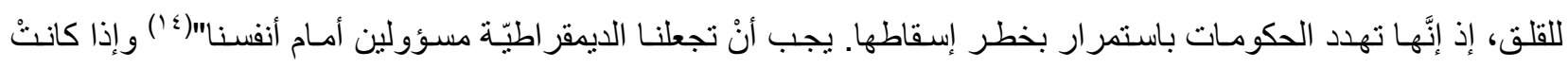

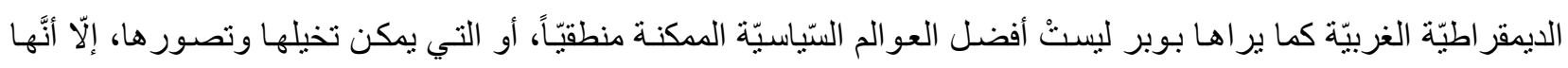


أفضل العو الم التي علمنا بوجودها واختبرناها، ومن هذه الوجهة نجده متفائلاً.(10) من هنـا تأتي المهمة الأخلاقيّة التي يعوّل

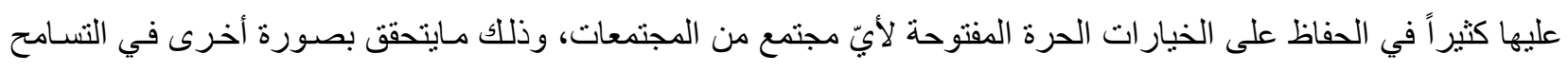
وتقبل المغاير و الثريك.

و التسامح عند بوبر هو: "النتيجة الحتميّة لإدر اكنا أنَّا لسنا معصومين من الخطأ. البشر خطاءون. نحن نخطيء طوال

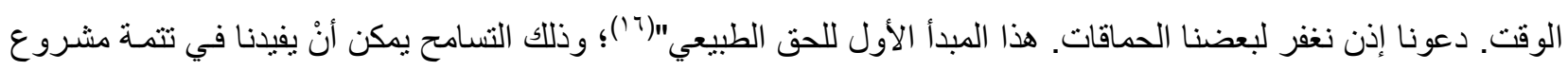

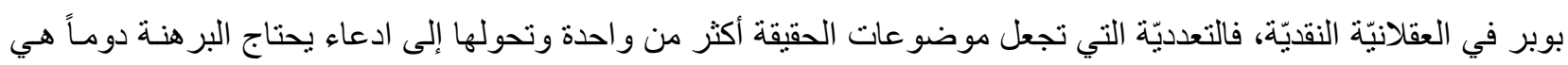

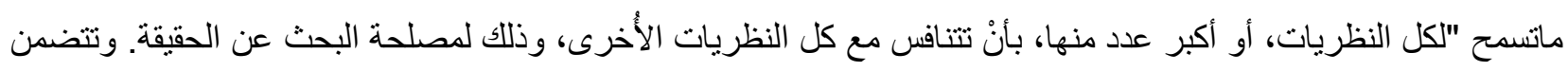

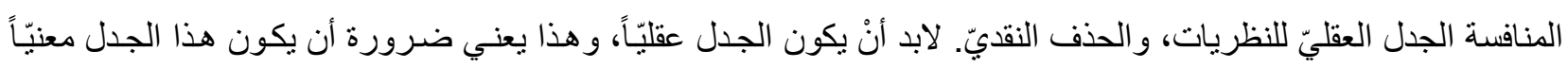

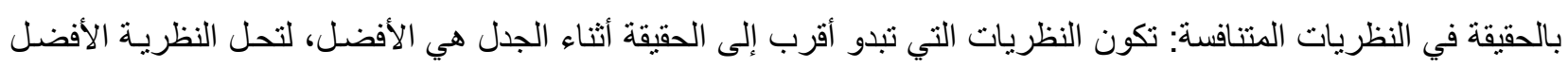

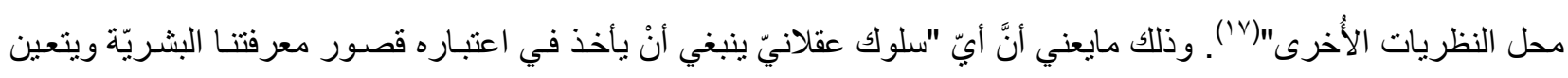

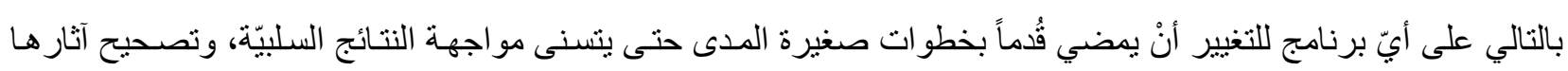

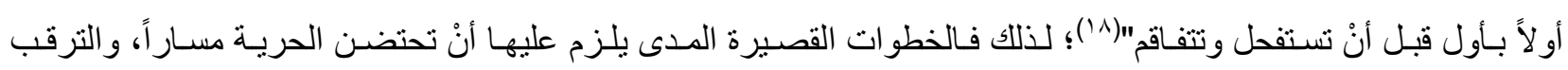
ومواجهة المشكلات أداةً، وتقبل المختلف، و عدم الانغلاق بوصفه ممارسة تسامحيّة ومرونة ضروريّة لديمومة المسار المفتوح للمجنمع.

يعد التسامح نوعاً من تطبيقات المجتمع المفتوح و العقلانيّة التي ينثدها بوبر، وفيه يقول: "يمكن التعبير عن وجهة

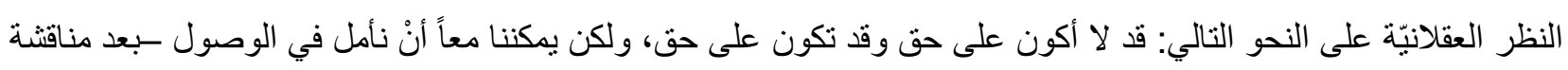

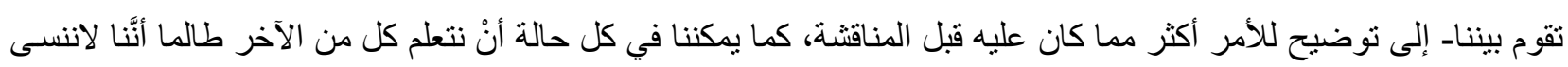

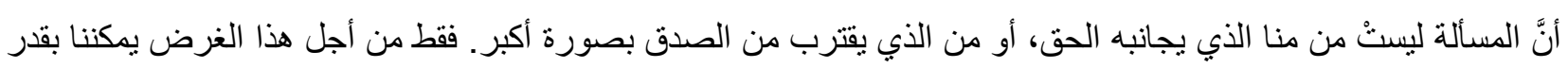

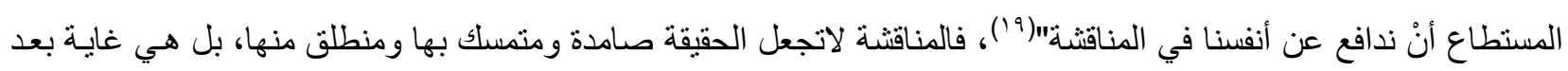

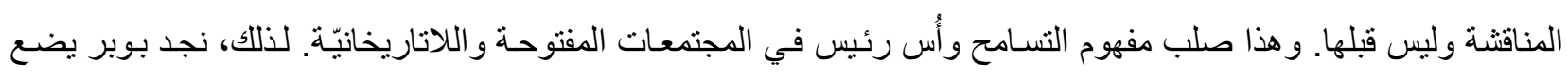

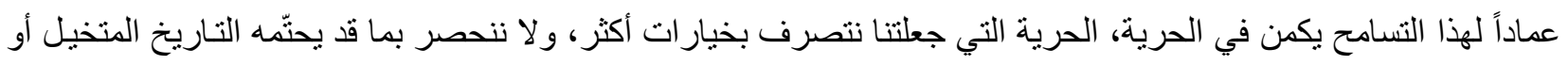
رأي الأموات.

والحرية هذه عليها أنْ تقودنا نحو التقام، نحو تجاوز الاقتصار على خيار واحد، وبالتالي القول بـالانغلاق الذي نقده

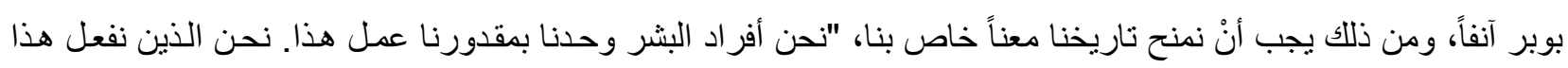

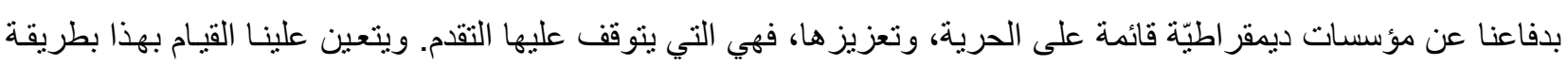

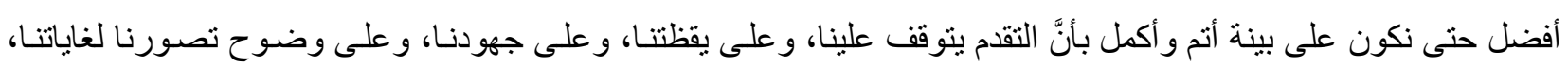
و على واقعيّة اختيار ها"(r).

يتبين إذن أنَّ التفسيرات العقلانيّة النقديـة للتـاريخ، و التـي يمكن قبول افتراضـها ومناقتنتها، هي نتـاج القول أصـلاً

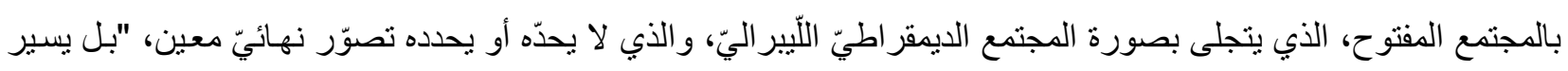

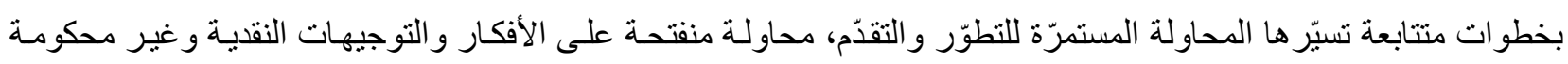

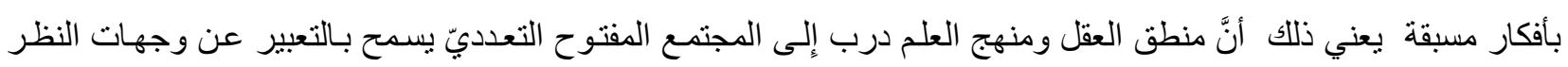

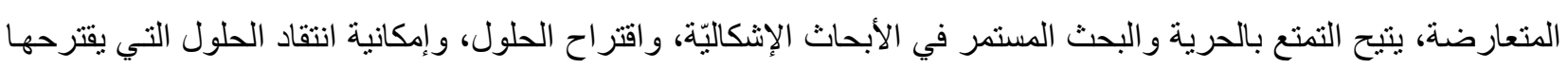

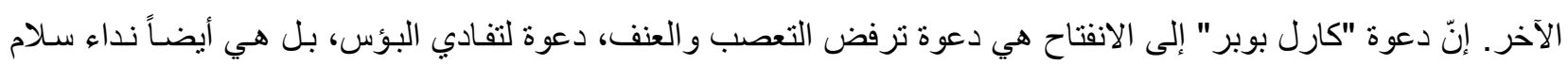


في مجتمع ديمقر اطيّ منفتح، وذلك يعود بالأساس إلىى فلسفته التي تدعو بالو عي بالمشكلات و العمل على حلها بيقظة نقديّة تحثُّ

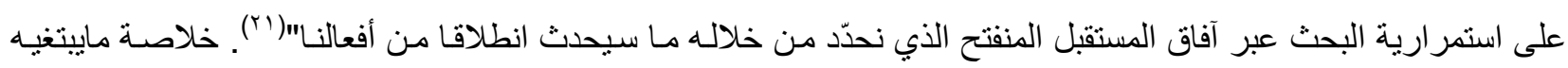

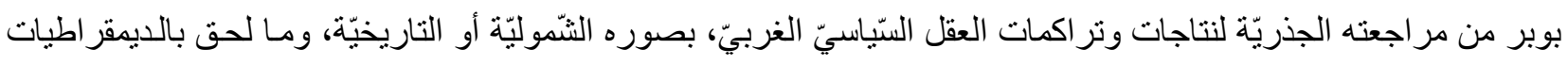

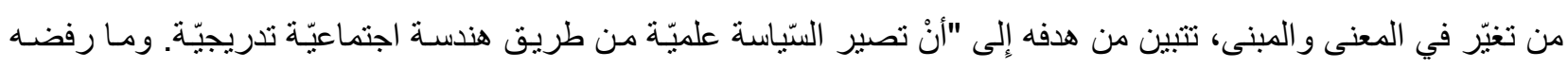

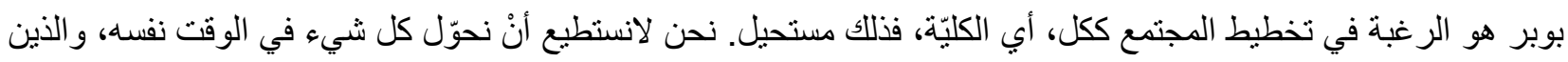

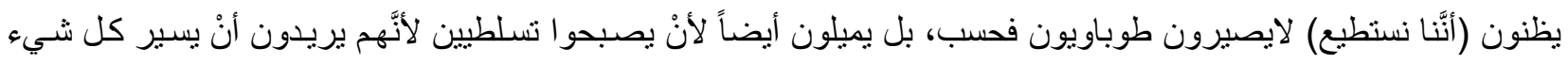

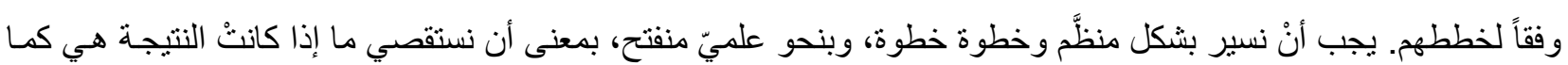
كنا افترضنا، ونكون راغبين بتكييف خططنا ونحن نتقام" (rr). ومما سبق تثبين مسألة التفتح بوصفها إمكانيات منبثقة دوماً على المستقبل، ومنه على اللاسكون وعدم القبول بالسـائد،

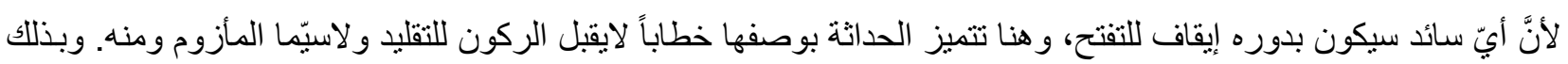

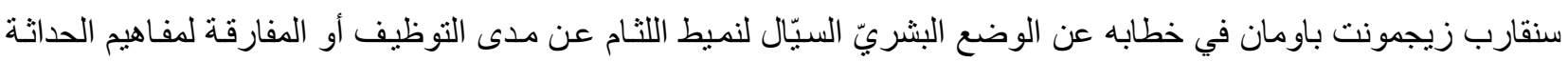
وخطاب كارل بوبر في التقتح.

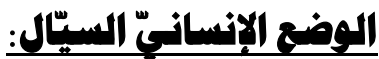

\section{وميادين الفكر والممارسة السيّالة:}

لعل السيولة أو الانسكاب الدائم يستدعي التغير الذي قدمه هرقليطس يوماً ما بعبارتهه: "إنَّك لاتنزل النهر مرتين" في

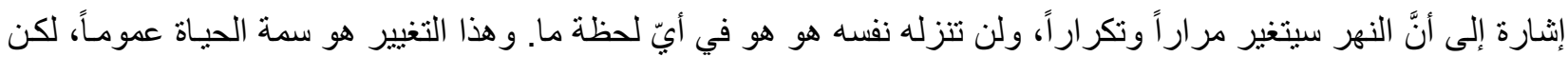

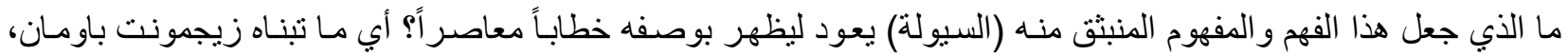
اعتقد أنْ هذه العودة ترتبط بتسويغ ظهور تعريف بودلير * للحداثة، في منتصف القرن التاسع عشر، ومن خـلال نصّـه "رسـام

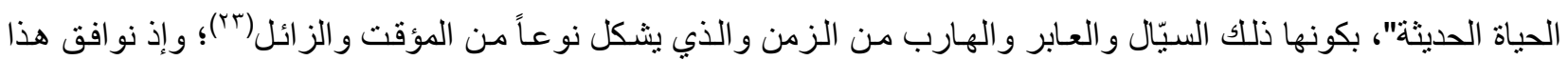

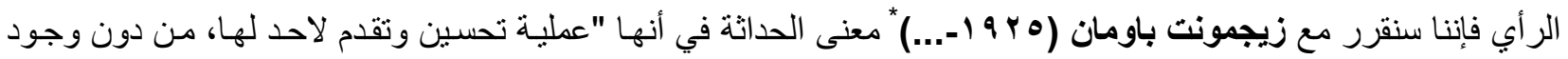

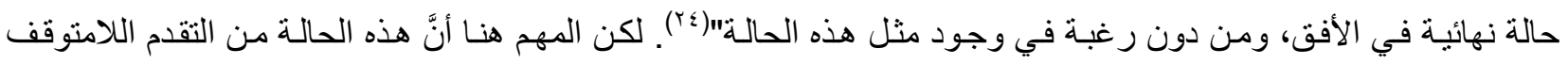

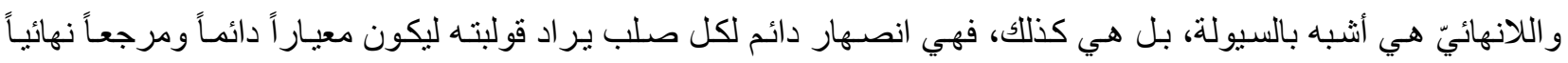

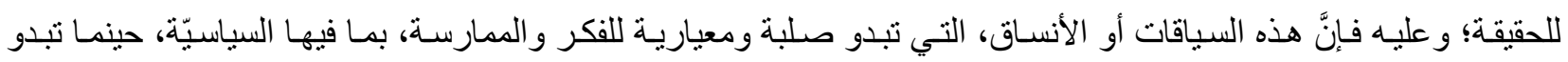

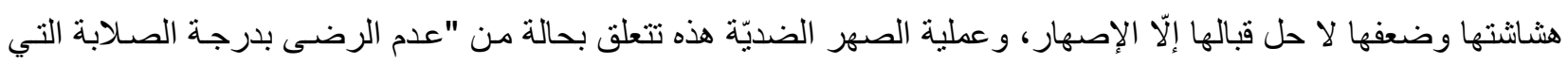

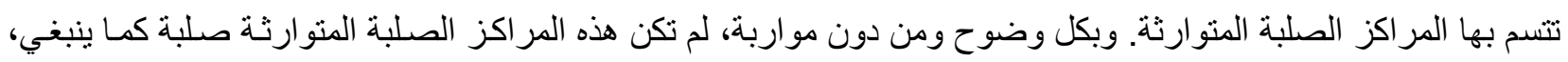

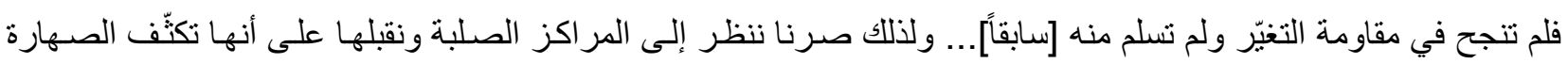

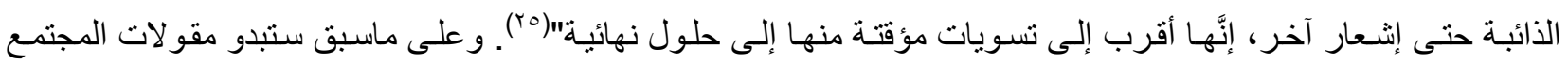

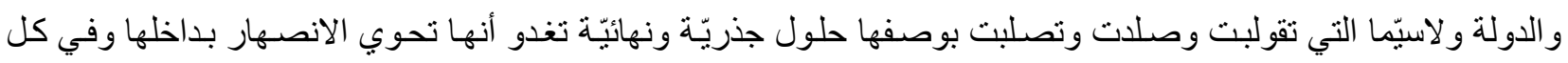
لحظة هي مهددة بالإفر اج عن ذلك السائل الذي يعني ضرورة تقدمها وتحسنها. لكن تلك السيولة ستكون من جهة ونة أخرى سبياً في جل مشكلاتتا الحياتيّة. و هذا التفاقم لحالة الميوعة والسيلان المستمر مصدره الحداثة بالتأكبد لأنه ماهيتها كذللك، فقد "كانت

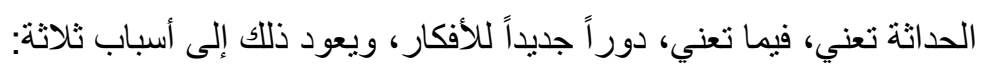
1ـ اعتماد الدولة على التعبئة الأيديولوجية من أجل تعزيز كفاءتها الوظيفية. r- الجنوح المعلن للدولة نحو التماثل و التجانس كما تجلى في ممارسات الحملات الصليبية الثقافية.

\section{-AYE.}




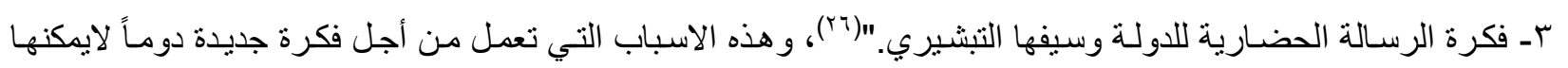

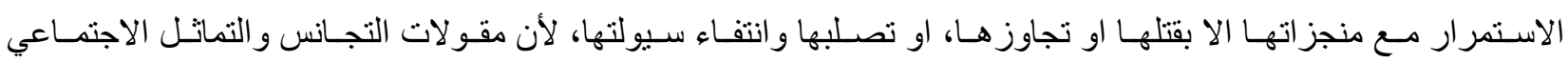
و الايديولوجيا الواحدة ستتسه ي تكلس روح الحداثة التي لايمكنها حينها ان تستمر بالتدفق بوصفها خطاباً وممارسةً سيالتان. ويعزى السبب الرئيس الآخر في السيولة، التي توسم بها أزمنتنا وحالنا، إلى "تفكيلك النُظم، بمعنى فصل السّلطة

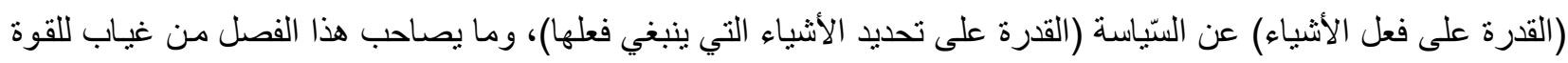

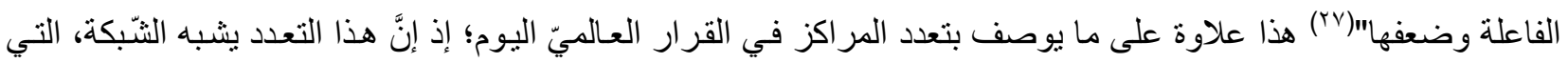

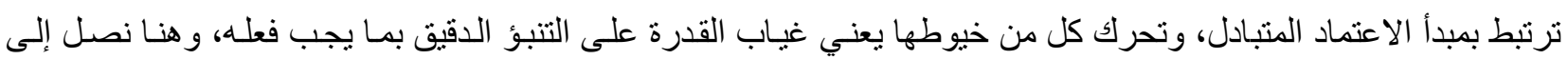

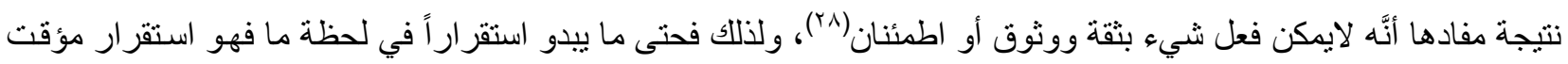

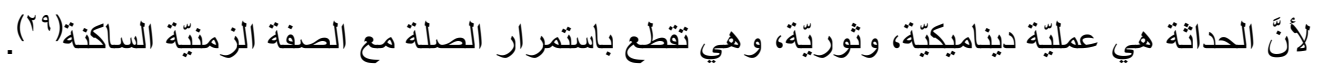
هذا الغياب ودوام السيلان بقدر ما يمثل علامة جو هريّة للحداثة إلّا أنَّهَ في الوقت نفسه صفة من صفات مابعد الحداثة،

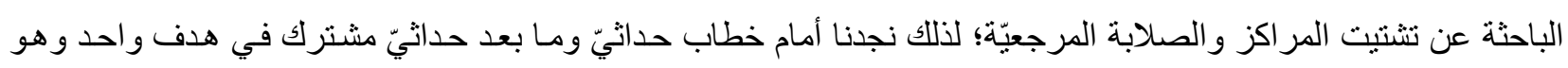
ديمومة التغيّر ، وهو ما يعبّر عنه بالثابت الوحيد.

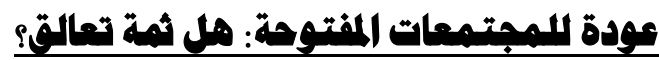

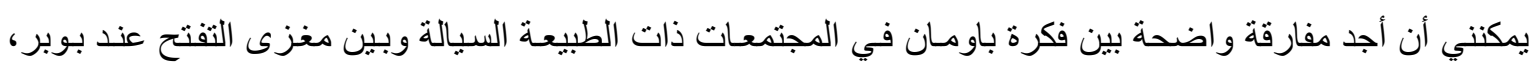

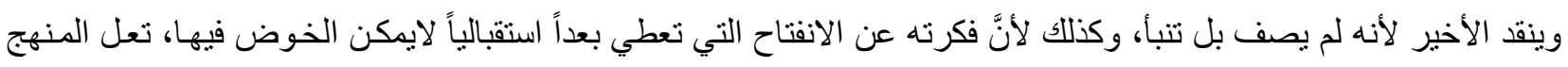

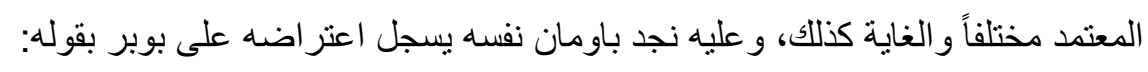
"لقد اكتسب انفتاح المجتمع اهتماماً جديداً لم يحلم به كارل بوبر، الذي سلَّ مصطلح المجتمع المفتوح، فماز زال هذا الانفتاح بسير إلى مجتمع يقر بصر احة بعدم اكتماله، ومن ثم يحرص بشدة على رعاية إمكاناته التي لم يعرفها بحدسه إلى الآن،

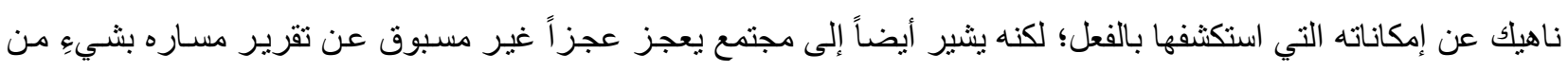

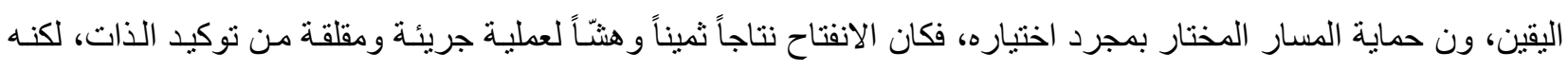

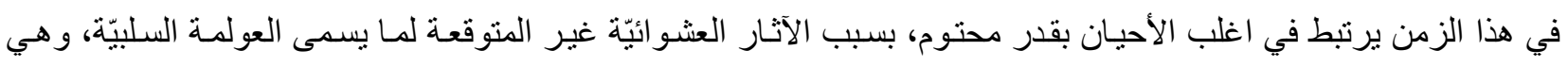

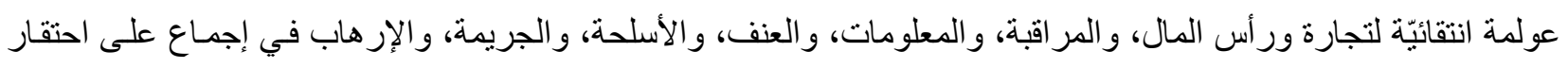

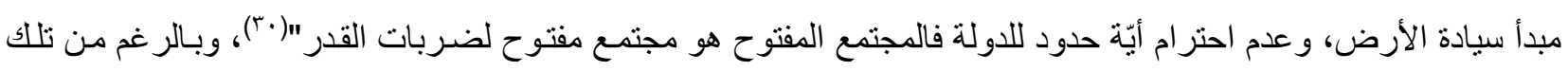

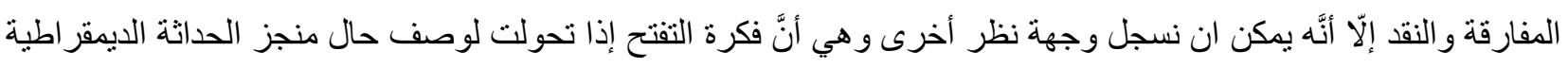

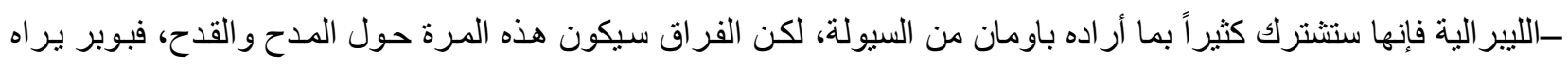

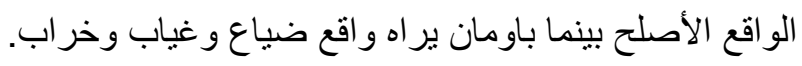

\section{صناعة الغراب في المتمعات السيالة:}

\section{الحداثة بين إنتاج النفاليات البشريّة واليات التغاص منها:}

يمكننا أن نجد وصفاً للخر اب الذي يرتبط بالمجمعات السيالة والوضع البشريّ الناتج منها عموماً بأنه الخر اب المتعلق

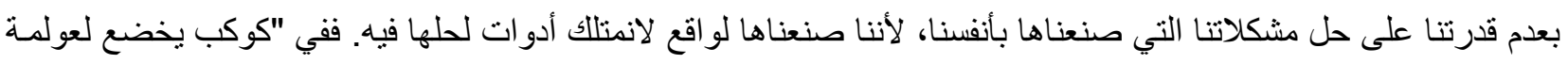

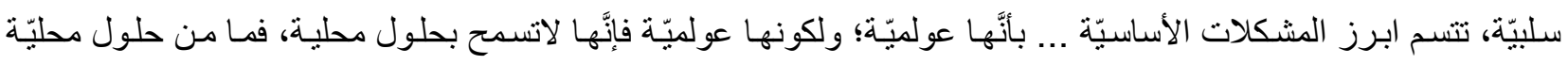

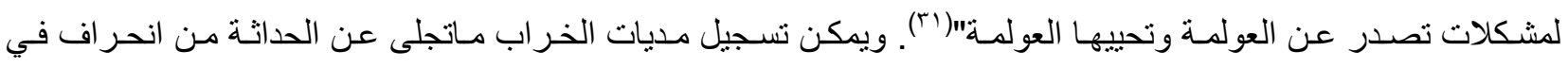

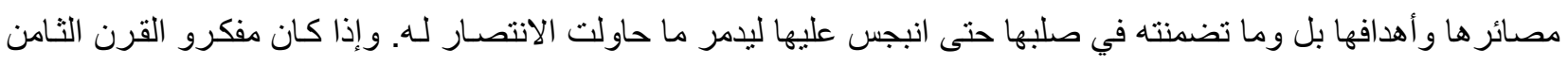

\section{-AYO}


عشر قد أر ادوا بتأسيسهم وتعزيز هم للحداثة أنْ ينتجو ا علماً موضو عبّاً ومبادئ أخلافيّة وقانون وفن مستقلات استقلالاً كافيّاً عن

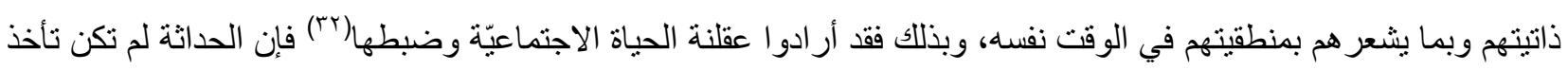

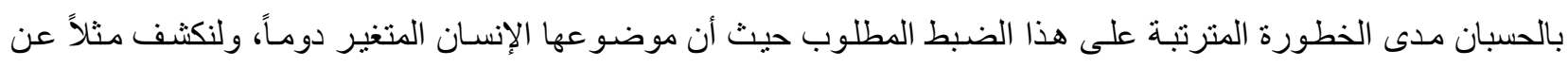
واحدة من اخطر منجزاتها: إنها إنتاج النفايات البشريّة والتخلص منها. يرى باومان أنَّ الحداثة قد استطاعتُ أن تنتج معدلات كبيرة من النفايات البشريّة واستمرتْ في ذلك، وهذه الإنتاجيّة توز عتنْ على قسمين:(rr)

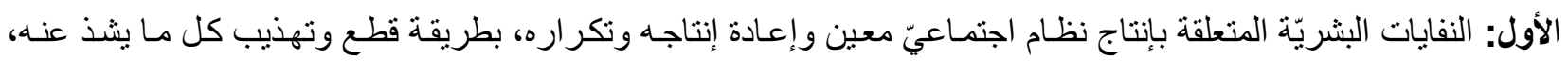

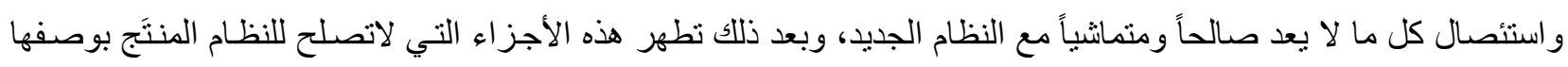
"نفايات" لا مو اد مفيدة.

الثاني: النفايات الناتجة عن التقدم الاقتصاديّ، و هذا النوع من منتجات الحداثة استطاع أنْ يصدر مسنويات ضخمة من النفايات

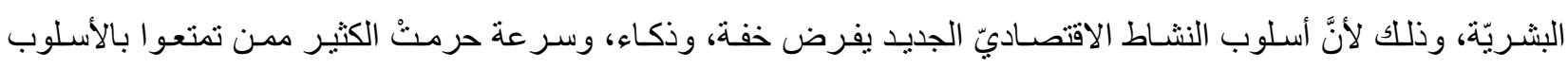

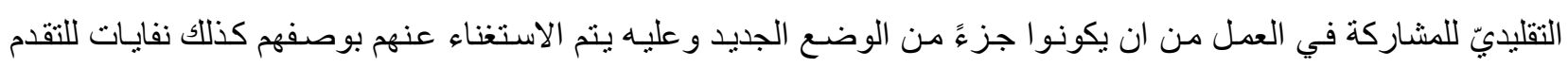

الاقتصاديّ.

وبعد ماتقدم من مخرجات للحداثة أدتْ إلى إفراز نفايـات بشريّة كبيرة، كانتُ المهمة الثنانية لها أنْ تتخلص من هذه

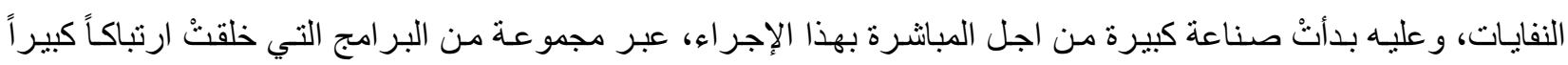

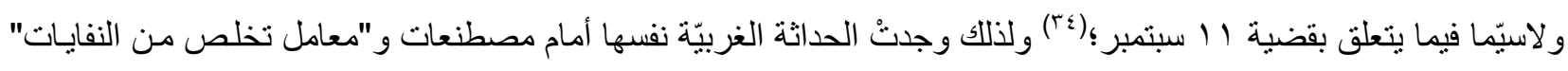

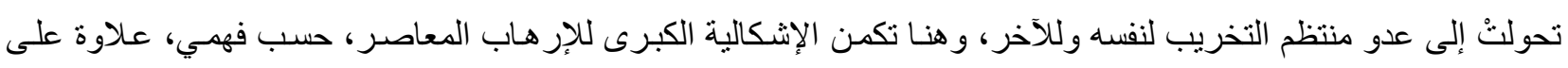
المحركات الأيديولوجيّة.

وقد يعتقد رجالات وضعنا السيال أنَّ الحرب على الإرهاب الذي تتعلق تتميته و التجارة بـه بمشروع التخلص من

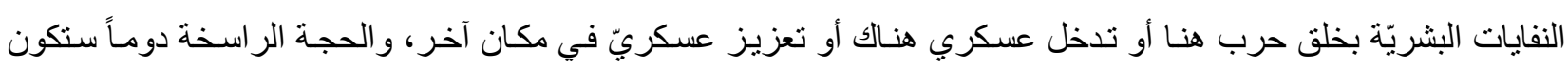

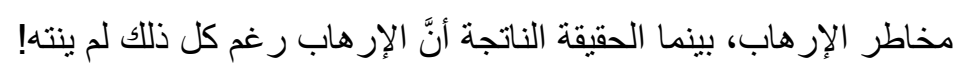

يقول باومـان: "الإرهـابيون على العكس مـن أعدائهم المعلنين، لايشـعرون أنَّهم مقيدون بـالموارد المحدودة التـي

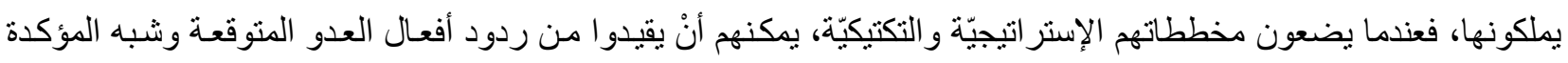

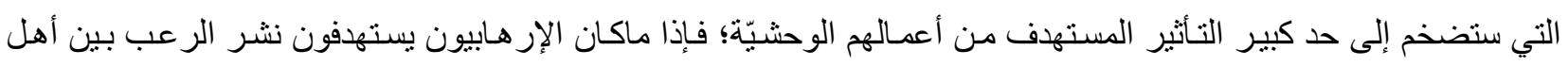

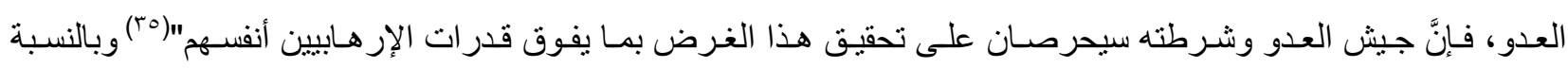

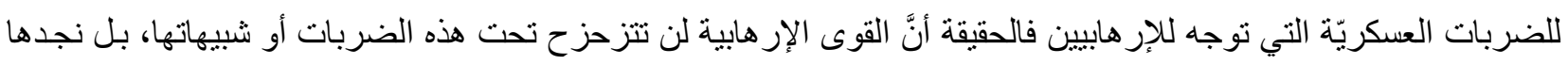

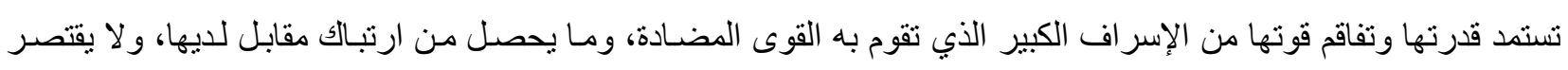

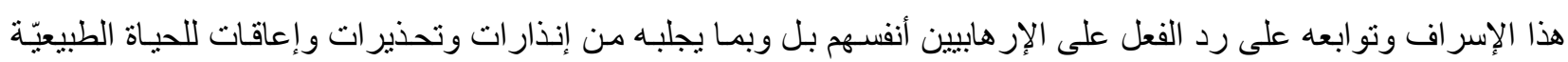

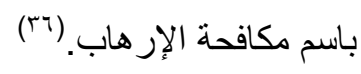
إنَّ ما لا يدخل في حسبان حراس الحروب و الإرهاب، أنَّ هناللك ماهو ماور اء الحاضر ، وهو مستقبل "الجرحى المقدّر

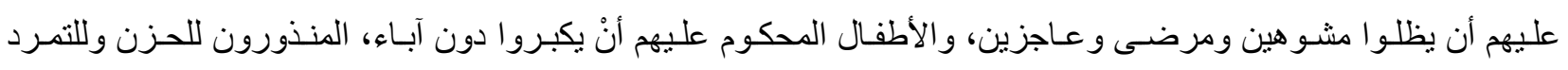

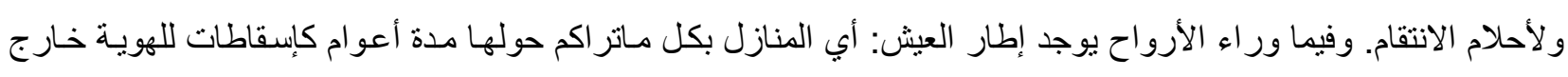


الذات. هناك الثوارع و الطرقات التي تصلها، هناك البنايات و الحقول و المشـاهد الطبيعية وقد تحولت إلى أنقاض و إلى ارض

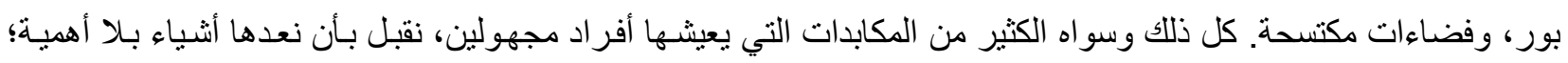

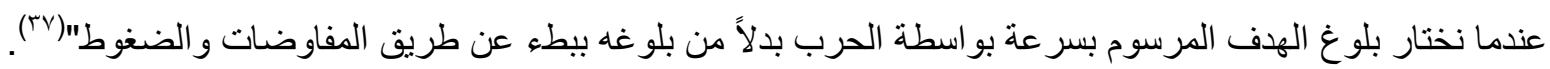
وقد يعتقد مسوغو الحروب وخالقو الإرهاب كرد فعل، "إنَّ كلمات مثل الديمقراطيّة و الحرية والازدهار لاتستحق قيمـة

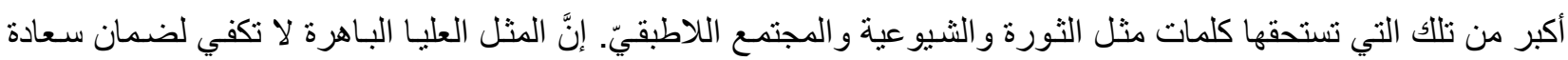
البشريّة: فعندما يتم العمل على دعمها، يهلك الأطفال و الثيوخ ويسيل الدم"(^)؛ ذللك لأن الحروب و لاسيّما التي سبق و أنْ

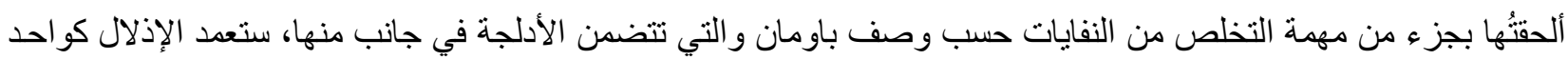
من صور التخلص والدفع في سبيل الاندماج في النظام العالمي أو الانتحار عبر الإرهاب، ذلك لأنَّ "الإذلال الو اقع أو المتخيل

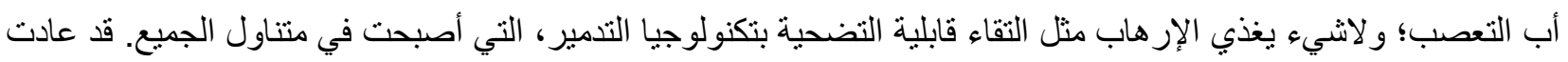

$$
\begin{aligned}
& \text { الاعتداءات منذ نهاية الحرب؛ فالإر هاب في صحة جيدة"(ra"). } \\
& \text { فهل يمكن ليوتوبيا ما أنْ تنقذ الو اقع بعد عجزه؟ }
\end{aligned}
$$

الحقيقة: إنَّه وبقدر ما مثلت اليوتوبيا أملاً لكثير من المجتمعات و على مر أزمنة غابرة وحتى راهنـة، إلا أنَّ الحقيقة إن

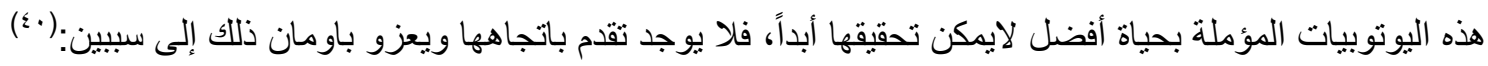
أولاً: إنَّ التقدم المفروض في اليوتوبيات ومطاردتها ومحاولة تحقيقها الزائفة تتمثل في فكرة الأرنب الدمية في سباقات الكلاب، فهي تطارده بضر اوة دون أنْ تمسك به أبداً. ثانياً: إنَّ هذا التقدم بل و اليوتوبيات عموماً وليس السعي لها، كان وكانت رد فعل على ماكان من الخر اب و الفنشل في المجرب

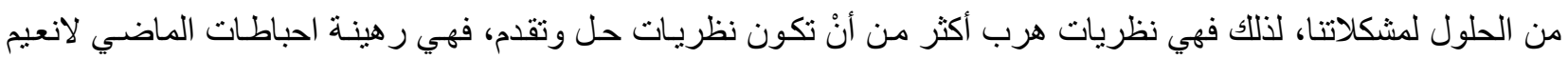
المستقبل.

وفي كل الأحو ال فإنَّ الوضع البشريّ السيّال لايمكنهـ إدر الك إنسـانيّة المهــة والوقوف عندها، لأنها سينفلت كذللك من

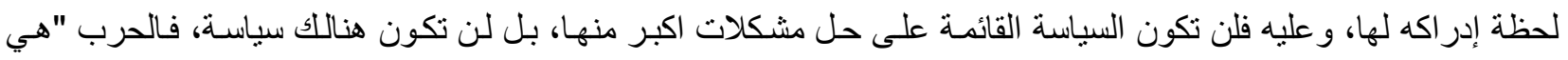

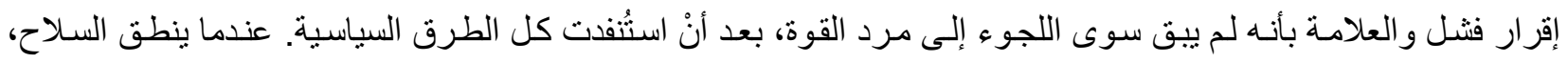

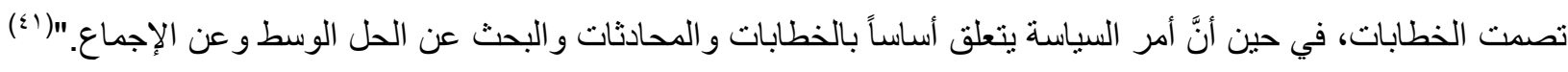

\section{فياب العدالة فياب لالسلام والأمهن:}

إنَّ غياب العدل هو المعوق الرئيس لإقامة السلام، لذلك نجد أنفسنا في مثل هكذا عصر ، خاضعين لمعايير لاتصلح لمشاكلنا، و السبب في ذللك هو:

أولاً: كثرة الثـبكات المتداخلـة لانتقـال المعلومـات، إذ لا فر اغـات و لا مجـالات و لا مجهو لات معرفيـة، لأن هنالك نـوع مـن

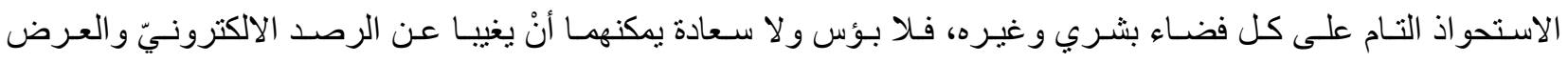
الصوريّّ؛ وحينها تكون قضية العدالة قضية شائكة يقرب حلها من الاستحالة.

ثانياً: في كوكب مفتوح ويعمل على إتاحة التنقل الحر للر أسمال والسلع، نجد أنَّا بمجرد أنْ يحدث حادث في مكان نؤثر حينها على الأمكنة الأخرى، مما يعطل طرق معيشتهم أو يحرفها ويغير ها، ولذللك فحتى الحياة الهانئة و المنعزلة ستكون محطّاً للتنأثر

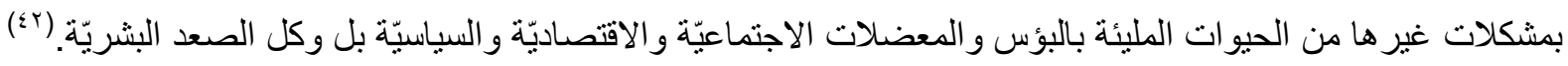


وفي هذا الحال فنحن منأكدون من أنَّ هنالك شبحاً (شبح العجز) يحوم "حول كوكب خاضـع لعولمـة سلبيّة، فنحن

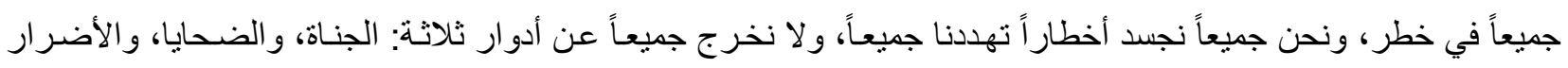

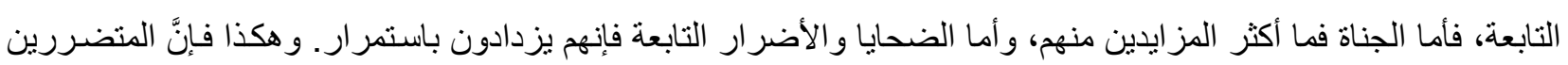

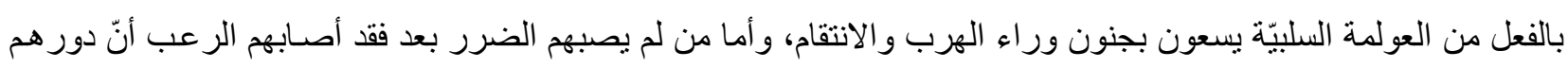

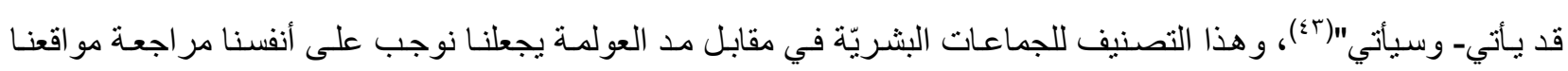
وفحص إمكاناتنا للخروج من هذه الثلاثية، ومن هذه الهيمنة الكلية التي ان لم نقف قبالها فإننا سنسحق بعجلتها. نحن إزاء و اقع معقد و مجتمعات متعددة الثقافات، لايمكن إدارتها من خلال مركز أو سلطة واحدة، وهي لا تتفق فيما

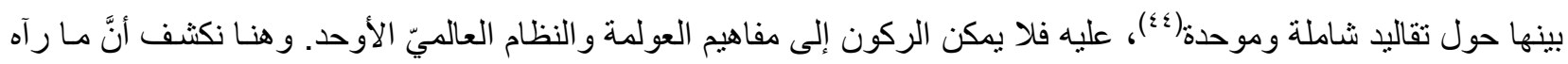
بوبر من تعدد و انفتاح سيكون طريقاً للخروج إلى الضوء، من نفق الحرب و والأيديولوجيّة القاتلـة، سيكون كلامهاً مغاير أ تمامـاً

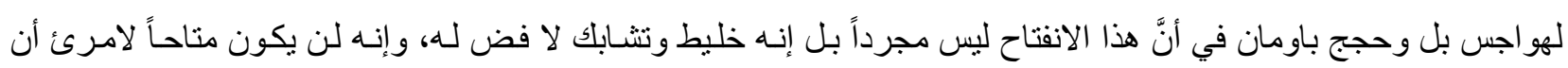
يرى الحل في أنموذج سياسيّ أوحد و أصلح كمعالجة لهموم متكاثرة ومنوز عة على مختلف رقع العالم الجغر افيّة.

\section{هراجعة لفصص فكرة التقدم، والسيرلة والانفتاه: هل من تلاقي بيز بهوبر وباومان؟}

قد يبدو أمر الوعد بالأفضل، وبناءً على ماتقدم يكون مزيجـاً بين اليوتوبيا وفكرة التفتح البوبريّة، سيكون محط شكك

وريبة ولا تسويغ له عقلاً.

ويورد باومان في هذا السياق إثكاليات عدة منها: هل التاريخ تقدم نحو معيثـة أفضل، وهل سيكون حافلاً بالسعادة؟

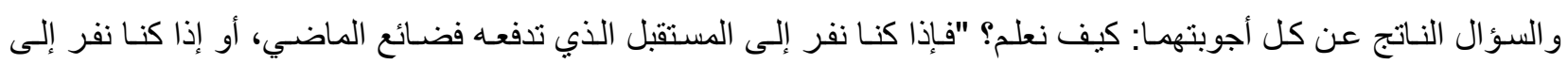

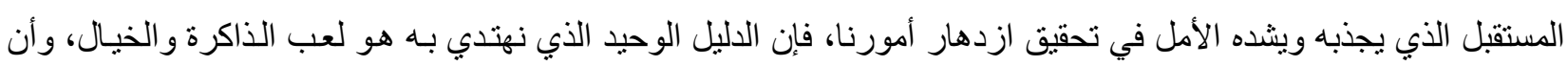

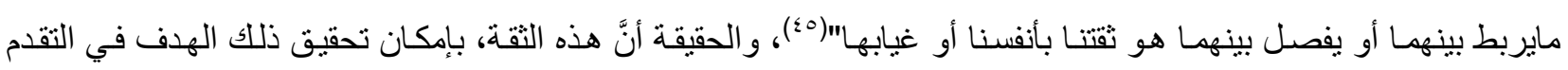

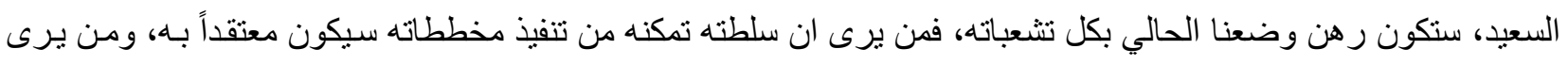

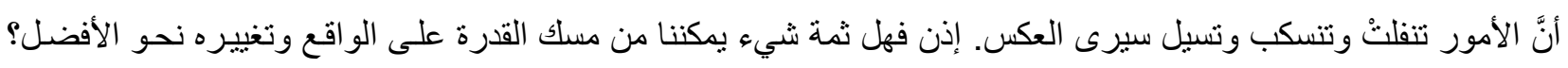

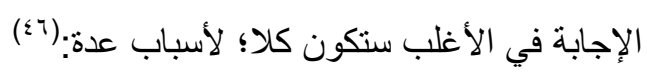

أو لاً: إنَّه لاتوجد قوة واحدة وكافية ومستقلة تستطيع أنْ تدفع العالم نحو الأمام، فالمشكلة بمن سيفعل ذللك، وليس ماذا نفعل لأجل

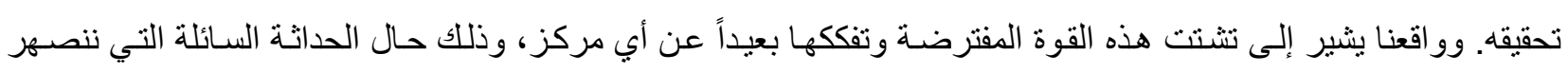

داخلها.

ثنانياً: غموض الدور الذي يمكن أنْ تؤديـه هذه القوة (القوة المستقلة)، في حال وجدت، من اجل تحسين العـالم، فكل الوعود

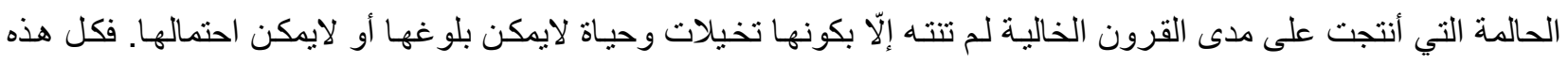

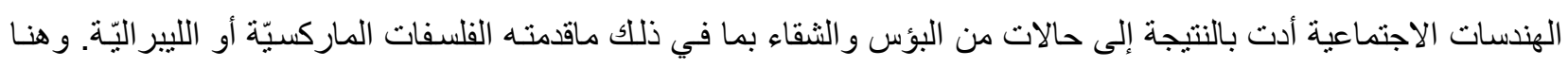

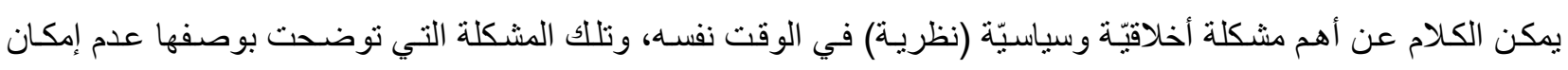

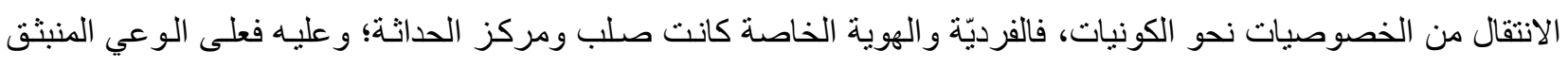

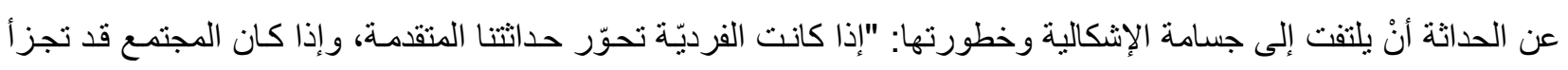
على هذا المنو ال إلى غبار لانهائيّ من [النرجسيّة]؛ فكيف يطلب للأخلاق النظرية مبدأ يتحلى بالصلاحيّة الكليّّ؟..... [لذلك فإنَّ]

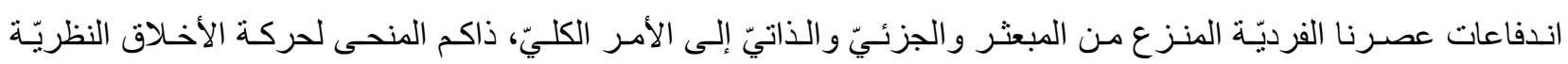




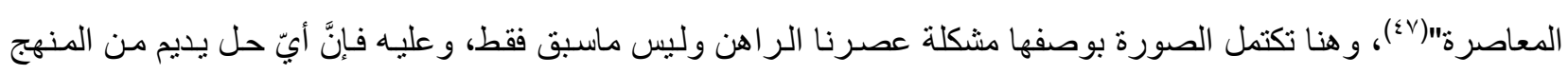

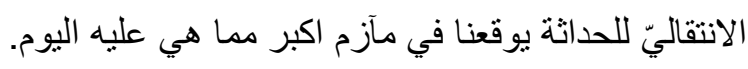

وبعد هذه الصورة التي تبدو متشائمة ومتطرفة وما بعد حداثيّة، نجد باومان يعود ليتفق مـع فكرة بوبر في أنَّ الحياة

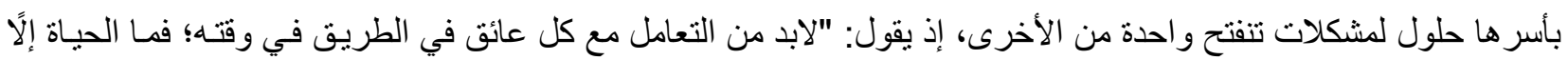

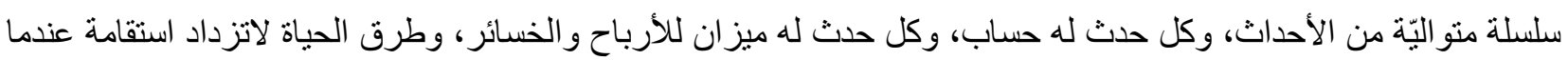

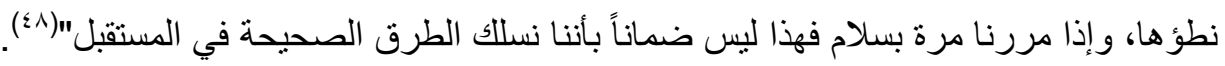
وبناءً على ماتقدم ستبقى مشكلة إمكانية التقدم، والتي يعدنا بها المجتمع المفتوح من جهة، و المجتمع المنغلق بحلم الايديولوجيا من جهة أخرى، مجرد ضياع في تصميم المستقبل، الذي يرنكز على حاضر، لعالم تهيمن عليه المرونـة والسيولة

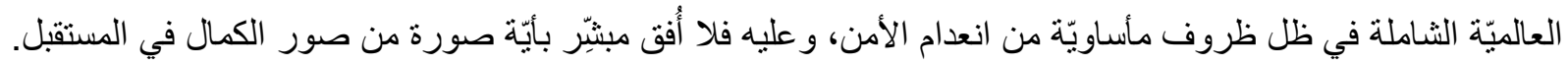

الخاتمة:

اتضح مما تقدم من مقارنتنا ومقاربتتا لرؤى بوبر وباومـان وتحليل ماتعلق بخطابيهما حول الوضع الإنساني بشقه

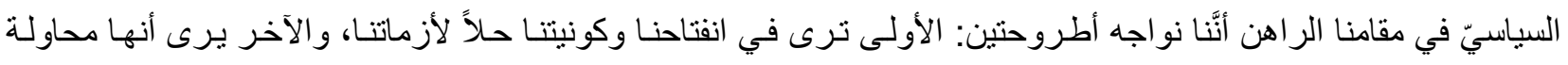

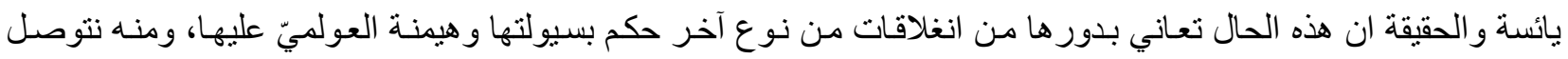
لنتائج منها:

ا - إنَّ المجتمعات المغلقة لايمكنها أنْ تكون حلاً لمجتمع إنسانيّ ما؛ لأنّها بالتأكيد ستسلب جو هره القائم على ممارسة الحرية. r- إنَّ أبيّ تصور ليوتوبيا ما بما فيها التفتح يعني أنَّنا نركن لرؤية واحدة غير مقدر لها الاختبار إلّا في كوننا جزءً مجازفاً فيه،

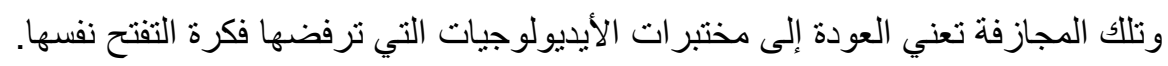
بـ- إنَّ فكرة التفتح هي أو المجتمع المفتوح هي رؤية أيديولوجية بينما فكرة السيولة هي وصف لمجتمعاتنا لا إقرار بما يجب أنْ تكون عليه في المستقبل، ولذلك فالفكرة الأولى تعني ان يجب ان ان نعمل من اجل ترسيخها بينما الثانية نوجب الخروج منها و عدم العمل لتحقيقها.

ع- إنَّ العنف المنولد عن الأيديولوجيات المغلقة سيستمر لأننا استبدلنا الايديولوجيا بأخرى، وما الخروج منه إلا عبر المواجهات

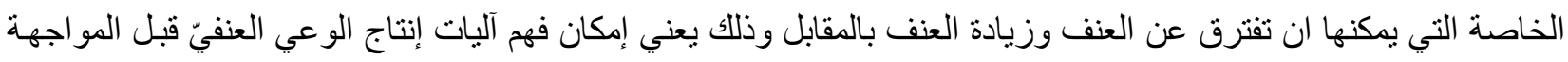
العنيّة التي بدور ها ستكرس الأول.

هواهش البحث

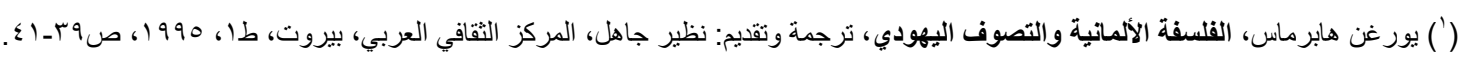

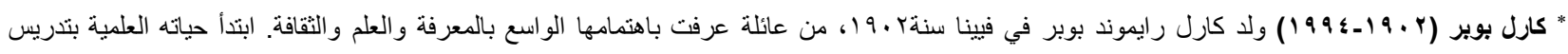

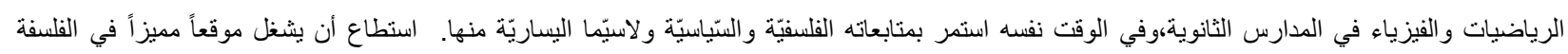

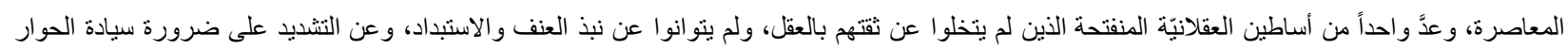

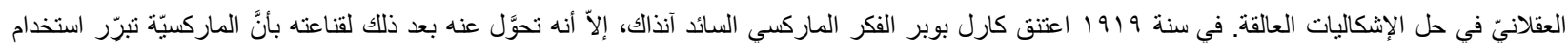

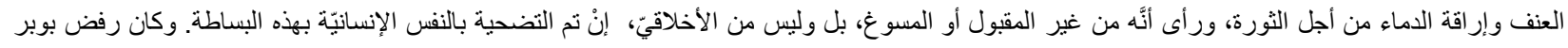

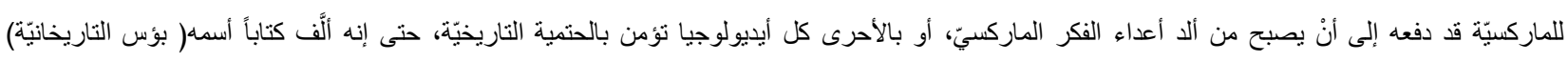

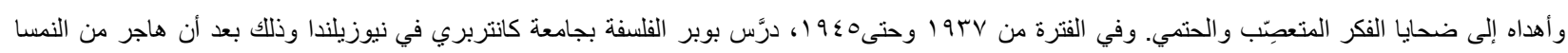

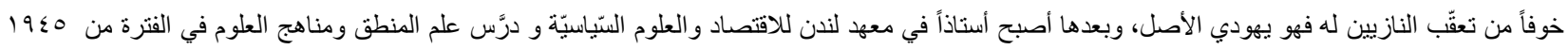

\section{$-1 Y 9$.}


وحتى 1979 وفي الوقت نفسه كان يلقي سلسلة من المحاضرات العامة في أكبر الجامعات الأمريكية. في سنة 1970 منحته ملكة بريطانيا لقب "سير" وهو أعلى تشريف تمنحه لمواطن. كما منحته الدنمارك جائزة" سوننغ "من جامعة كوبنهاغن التي لم يحصل عليها إلاّ شخصيات مثل برتراند رسل. واستمر بإلقاء المحاضرات حتى بعد تقاعده حتى و افته المنية في عام بو 199

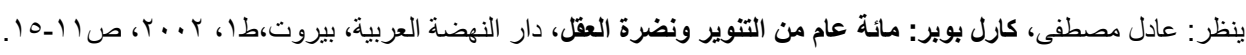

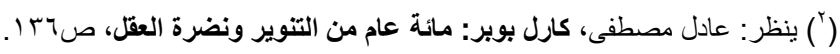

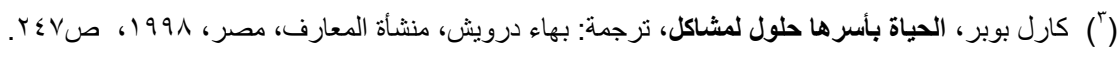

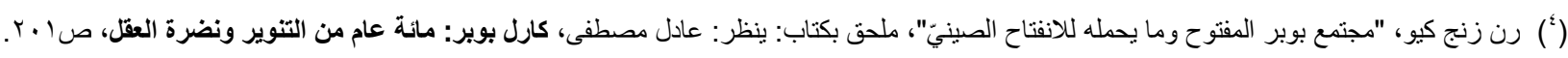

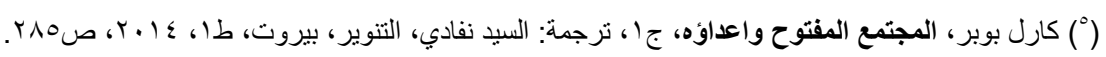

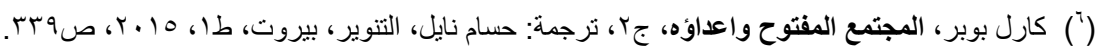

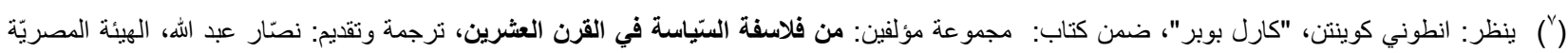

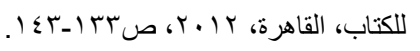

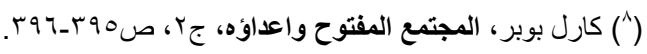

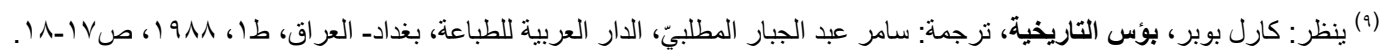

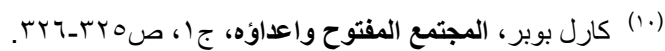

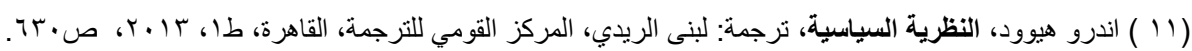

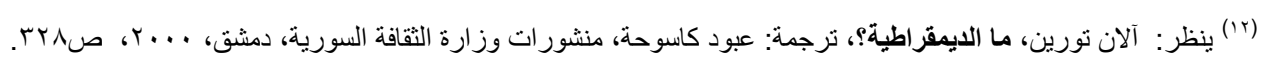

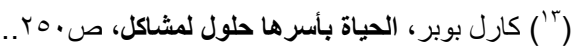

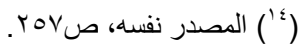$$
\text { ( IVV) }
$$

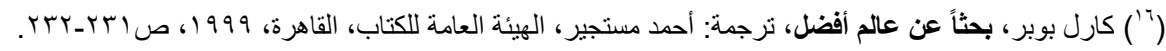

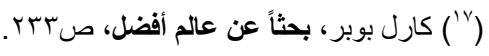
(1) ) انطوني كوينتون، "كارل بوبر"، ضمن كتاب: مجموعة مؤلفين، أعلام الفلسفة السياسية المعاصرة، تحرير: انطوني دي كرسبني وكينيث مينوج، الهيئة العامة

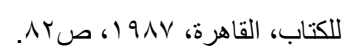

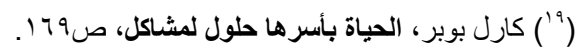

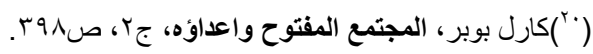
(") سعاد حمداش، "ابستمولوجيا الفكر السيّاسيّ لكارل بوبر: قر اءة في فلسفة الانفتاح و العقلانيّة النقديّة"، ضمن كتاب مجموعة مؤلفين: الفلسفة السيّيَّيّة المعاصرة من

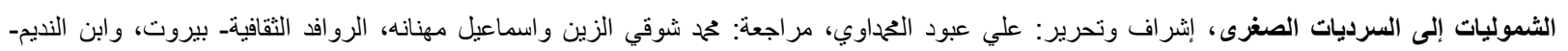

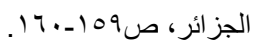
(r (Y) غنار سكيربك، ونلز غيلجي، تاريخ الفكر الغربي: من اليونان القديمة الى القرن العشرين، ترجمة: حيدر حاج اسماعيل، المنظمة العربية للترجمة، بيروت،/طا، . 1910 ص.

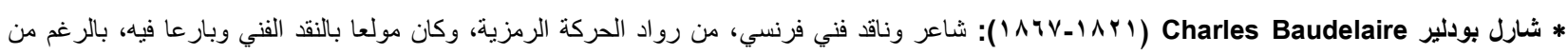

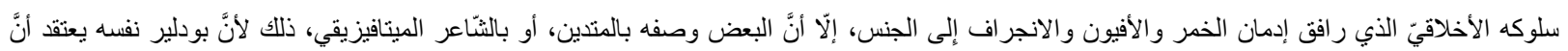

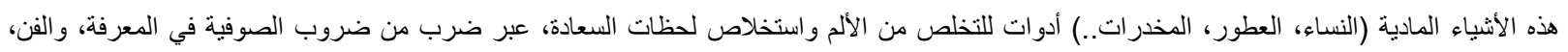

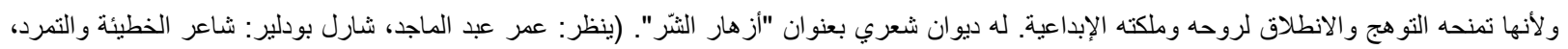

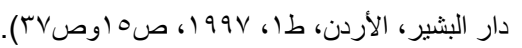

${ }^{\left({ }^{\top}\right)}$ See: Charles Baudelaire, The Painter of Modern Life (1Атr), 


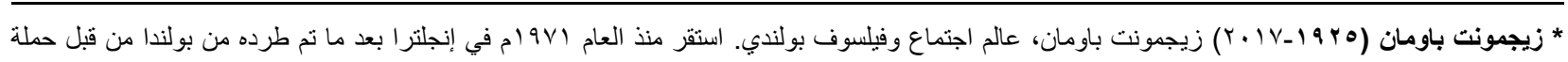

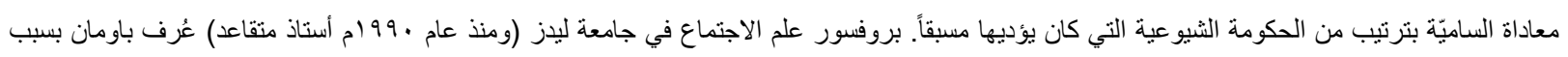

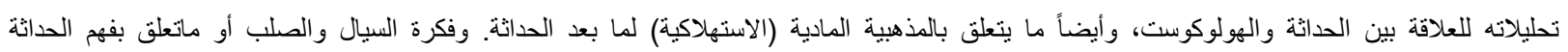

$$
\text { و المجتمعات المعاصرة بوصفها تجليات لحالات السيلان. }
$$

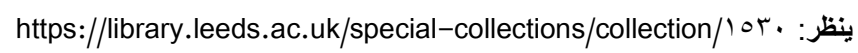

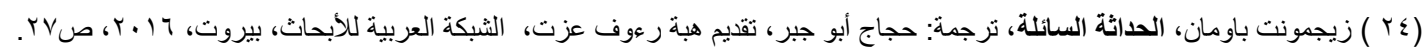
(ro)

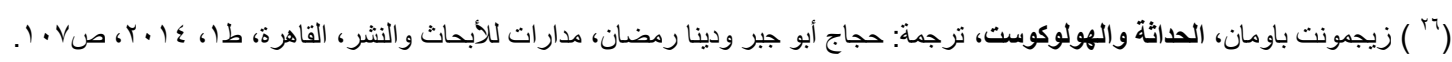

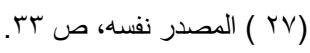
( Y ( المصدر نفسه، صبr)

(`9) See: John Leonard, Modernity, CPN publications PTY, Australia, 1997, p. 1 r.

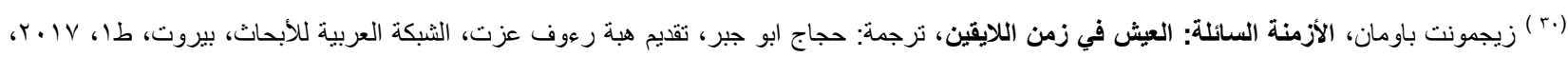
ص.r-r.

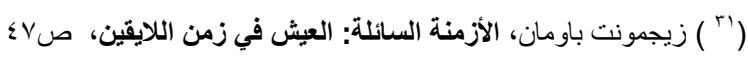

$\left({ }^{r r}\right)$ See: Habermas, Jurgen, "Modernity versus Postmodernity", New German Critique, No. rr, 191 ।, p.9.

("rr ) ينظر: زيجمونت باومان، الحب السائل: عن هشاثة الروابط الإنسانتّة، ترجمة: حجاج ابو جبر، تقديم هبة رعوف عزت، الثبكة العربية للأبحاث، بيروت، طا، $.179-171$ ص. 179

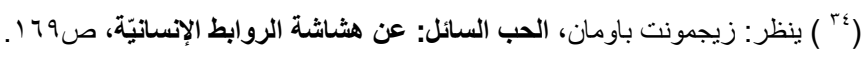

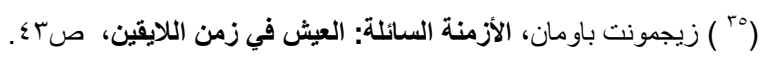

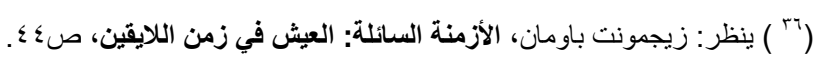

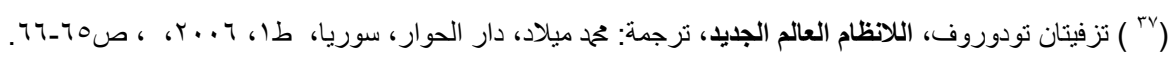

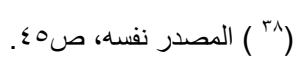

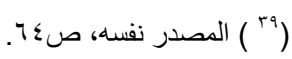

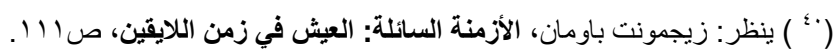

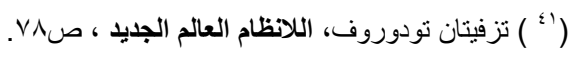

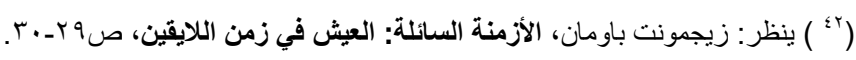

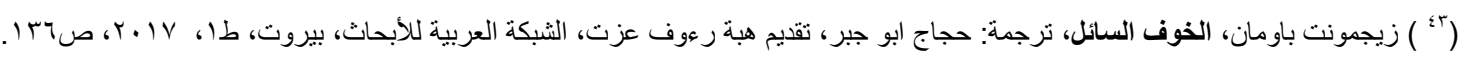

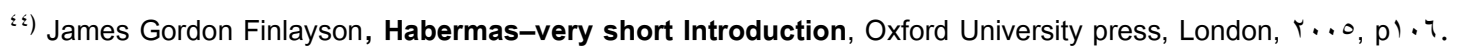

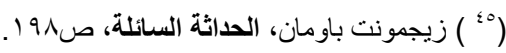

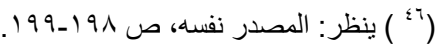

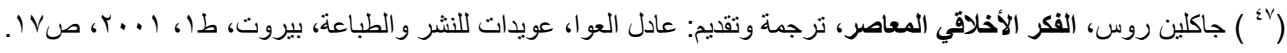

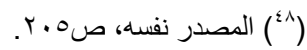

